\title{
Utilização de indicadores para estimar a digestibilidade aparente em gatos
}

[Use of markers to estimate the apparent digestibility in domestic cats]

\author{
R.S. Vasconcellos ${ }^{1}$, A.C. Carciofi ${ }^{2} *$, L.D. Oliveira ${ }^{1}$, F. Prada ${ }^{3}$, G.T. Pereira ${ }^{2}$ \\ ${ }^{1}$ Aluno de pós-graduação - UNESP - Jaboticabal, SP \\ ${ }^{2}$ Faculdade de Ciências Agrárias e Veterinárias - UNESP \\ Via de Acesso Prof. Paulo Donato Castellane, s/n \\ 14.884-900 - Jaboticabal, SP \\ ${ }^{3}$ Universidade de São Paulo - São Paulo, SP
}

\begin{abstract}
RESUMO
Compararam-se os métodos de coleta total (CT) e dos indicadores óxido crômico (Cr2O3), cinzas insolúveis em ácido (CIA) e lignina na determinação dos coeficientes de digestibilidade aparente (CDA) dos nutrientes para gatos. Os CDA de quatro rações foram determinados pela CT e estimados pelos diferentes indicadores em teste. Foram utilizados 24 gatos adultos castrados, alojados em gaiolas metabólicas individuais, totalizando seis animais por ração. $\mathrm{O}$ experimento seguiu um delineamento inteiramente ao acaso, em parcelas subdivididas, sendo as rações as parcelas, os métodos as subparcelas e cada gato uma unidade experimental. Os CDA foram significativamente menores pelo método da lignina em uma das rações estudadas $(\mathrm{P}<0,05)$. Os métodos $\mathrm{Cr} 2 \mathrm{O} 3$, CIA e CT resultaram em CDA iguais em todas as rações $(\mathrm{P}>0,05)$. As taxas de recuperação dos indicadores, médias \pm erro-padrão da média, foram, respectivamente, de $97,1 \pm 2,5 \%, 97,3 \pm 2,9 \%$ e $83,9 \pm 9,1 \%$ para o $\mathrm{Cr} 2 \mathrm{O} 3$, CIA e lignina. A CIA e o Cr2O3 mostraram grande potencial para utilização como indicadores, enquanto a ampla variabilidade dos resultados obtidos com a utilização da lignina não justificou seu emprego como substância índice para felinos.
\end{abstract}

Palavras-chave: gato, óxido crômico, lignina, cinzas insolúveis em ácido, digestibilidade aparente

\begin{abstract}
The total collection (TC) method was compared to chromium oxide $\left(\mathrm{Cr}_{2} \mathrm{O}_{3}\right)$, acid-insoluble ash (AIA) and lignin marker methods for determining the coefficients of apparent digestibility (CAD) of nutrients in domestic cats. The CAD of four diets were determined by TC and estimated for the three markers through tests. Twentyfour adult neutered cats were housed in individual metabolic cages, totaling six animals per diet. The experiment was carried out using a completely randomized design in subdivided blocks where diets were blocks, methods were sub-blocks and each cat an experimental unit. CAD for the lignin method was significantly lower than TC method $(P<0.05)$ in one of the studied diets. $\mathrm{CAD}$ for the $\mathrm{Cr}_{2} \mathrm{O}_{3}, \mathrm{AIA}$ and TC methods were similar in all diets. Recuperation rates of $\mathrm{Cr}_{2} \mathrm{O}_{3}$, AIA and lignin markers were 97.1 $2.5 \%$, $97.3 \pm 2.9 \%$ and $83.9 \pm 9.1 \%$ respectively. AIA and $\mathrm{Cr}_{2} \mathrm{O} 3$ methods showed high potential for use as markers while the higher variability in results obtained with the use of lignin did not justify its usage as an indicator substance for felines.
\end{abstract}

Keywords: cat, chromium oxide, lignin, acid insoluble ash, apparent digestibility

\section{INTRODUÇÃO}

A digestibilidade dos alimentos pode ser determinada in vivo pelo método de coleta total

Recebido em 6 de maio de 2005

Aceito em 14 de novembro de 2006

*Autor para correspondência (corresponding author)

E-mail: aulus.carciofi@gmail.com de fezes, ou estimada com o uso de indicadores (Andreasi, 1956). O método dos indicadores representa uma alternativa à coleta total quando se torna difícil ou inconveniente mensurar-se a ingestão ou coletar-se totalmente as fezes 
(Zeoula et al., 1992). Recuperação completa e precisão na determinação laboratorial dos indicadores são essenciais para que essas substâncias sejam consideradas apropriadas para o uso em ensaios de digestibilidade (Saha e Gilbreath, 1991).

Em gatos domésticos, o óxido crômico tem sido o indicador mais utilizado na avaliação da digestibilidade e taxa de passagem dos alimentos pelo trato digestório (Pencovic e Morris, 1975; Hendriks et al., 1996; Peachey, 2000). Apesar disso, não foram encontrados na literatura estudos que apresentassem informações sobre sua taxa de recuperação, nem tampouco validando-o frente à coleta total de fezes.

Uma preocupação em relação ao crômio é seu potencial efeito cancerígeno para o pesquisador e o animal experimental. $\mathrm{O}$ cromo trivalente, como encontrado no óxido crômico, é muito pouco reativo com o DNA, além de ser pobremente absorvido pela membrana celular, ao contrário do cromo hexavalente, presente em dicromatos solúveis ou outros complexos do cromo, que apresenta alta reatividade e solubilidade nas membranas (Ferreira, 2002; Bastarache, 2005). O emprego de óxido crômico anidro também aumenta a segurança do procedimento por ser altamente insolúvel e estável em diferentes condições de $\mathrm{pH}$ e temperatura. No entanto, a solubilização do cromo para posterior quantificação laboratorial forma dicromatos, o que torna indispensável o cuidado com o manuseio e o descarte do resíduo de análise (Pauling, 1966).

Embora os gatos sejam animais classificados pelo seu hábito alimentar como carnívoros estritos, os alimentos comerciais para esta espécie apresentam grande quantidade de ingredientes de origem vegetal em sua composição (Crane, 2000). Esse fato poderia viabilizar o emprego das cinzas insolúveis em ácido (CIA) e da lignina como indicadores internos nos estudos de digestão, substâncias até então não estudadas para a espécie. Carciofi et al. (1998) encontraram taxa de recuperação da fibra em detergente ácido (FDA) e fibra bruta (FB) próximas a $100 \%$ em gatos.

Este trabalho teve por objetivo comparar, em gatos domésticos, os coeficientes de digestibilidade aparente obtidos pelo método de coleta total àqueles estimados pelos indicadores óxido crômico, CIA e lignina.

\section{MATERIAL E MÉTODOS}

Foram utilizadas quatro rações experimentais para gatos, denominadas R1, R2, R3 e R4, formuladas para atender as recomendações nutricionais da Association... (2004). Essas apresentavam composição nutricional semelhante e variaram apenas quanto ao principal ingrediente de origem vegetal (milho, sorgo, farinha de mandioca ou quirera de arroz), permitindo-se com isso quatro avaliações de cada método. Adicionou-se $\mathrm{Cr}_{2} \mathrm{O}_{3}$ na mistura dos ingredientes das rações, anteriormente à extrusão, como indicador externo, de forma a obter-se uma concentração final de $0,35 \%$ na matéria seca. A lignina e as CIA foram utilizadas como indicadores internos. A fórmula e a composição química das rações, incluindo a concentração dos indicadores, encontram-se na Tab. 1.

Foram utilizados 24 gatos adultos, sem raça definida, com peso médio de $4,28 \pm 0,56 \mathrm{~kg}$. Os animais foram divididos aleatoriamente em quatro grupos de seis gatos, cada um recebendo uma das rações experimentais. A digestibilidade foi estimada em cada grupo utilizando-se quatro métodos: coleta total, lignina, $\mathrm{Cr}_{2} \mathrm{O}_{3}$ e CIA.

Todos os animais foram mantidos em gaiolas metabólicas individuais em inox, com dimensões de $80 \times 80 \times 90 \mathrm{~cm}$ durante o experimento, que teve duração de 14 dias, sendo sete dias de adaptação e sete de coleta total de fezes. Durante todo o período experimental, o alimento foi fornecido aos animais duas vezes ao dia (7h30min e 17h30min), e as sobras quantificadas imediatamente antes da próxima refeição. As quantidades fornecidas foram estimadas segundo a equação do Nutrient... (1986). As fezes de cada gato foram coletadas duas vezes ao dia, pesadas e congeladas para posterior análise.

Ao final do período de coleta, as fezes foram descongeladas e homogeneizadas, compondo uma única amostra por animal, que foi posteriormente seca em estufa com ventilação forçada a $65^{\circ} \mathrm{C}$ durante 72 horas e moídas em micromoinho, em peneira de $1 \mathrm{~mm}$, para proceder-se às análises laboratoriais. 
Tabela 1. Ingredientes, composição química e concentração dos indicadores nas rações experimentais

\begin{tabular}{|c|c|c|c|c|}
\hline Ingrediente & Ração 1 & Ração 2 & Ração 3 & Ração 4 \\
\hline Fonte de amido $^{1}$ & 45,66 & 53,49 & 42,49 & 59,27 \\
\hline Farinha de vísceras de frango & 24,00 & 24,00 & 24,00 & 23,00 \\
\hline Proteína isolada de soja & 16,08 & 9,94 & 17,01 & 5,16 \\
\hline Óleo de frango & 3,69 & 2,00 & 5,93 & 2,00 \\
\hline Ovo integral desidratado & 2,50 & 2,50 & 2,50 & 2,50 \\
\hline Casca de soja & 2,00 & 2,00 & 2,00 & 2,00 \\
\hline Levedura de cerveja & 1,50 & 1,50 & 1,50 & 1,50 \\
\hline Fígado bovino desidratado & 1,50 & 1,50 & 1,50 & 1,50 \\
\hline Taurina & 0,20 & 0,20 & 0,20 & 0,20 \\
\hline Fosfato bicálcico & 0,90 & 0,90 & 0,90 & 0,90 \\
\hline Carbonato de cálcio & 0,70 & 0,70 & 0,70 & 0,70 \\
\hline Citrato de potássio & 0,40 & 0,40 & 0,40 & 0,40 \\
\hline Cloreto de sódio & 0,40 & 0,40 & 0,40 & 0,40 \\
\hline Óxido crômico & 0,35 & 0,35 & 0,35 & 0,35 \\
\hline Premix mineral/vitamínico ${ }^{2}$ & 0,1 & 0,1 & 0,1 & 0,1 \\
\hline Antifúngico $^{3}$ & 0,1 & 0,1 & 0,1 & 0,1 \\
\hline L-lisina & 0,06 & 0,06 & 0,06 & 0,06 \\
\hline DL-metionina & 0,05 & 0,05 & 0,05 & 0,05 \\
\hline Antioxidante $^{4}$ & 0,01 & 0,01 & 0,01 & 0,01 \\
\hline Nutriente & \multicolumn{4}{|c|}{ Composição química (valores na matéria seca) } \\
\hline Proteína bruta $(\%)$ & 36,42 & 31,78 & 32,46 & 28,78 \\
\hline Gordura em hidólise acida (\%) & 12,73 & 11,81 & 12,96 & 9,99 \\
\hline Matéria orgânica (\%) & 92,58 & 91,46 & 92,05 & 92,94 \\
\hline Matéria mineral (\%) & 7,42 & 8,54 & 7,95 & 7,06 \\
\hline Lignina $(\%)$ & 1,96 & 1,00 & 0,84 & 1,35 \\
\hline Cinzas insolúveis em ácido (\%) & 0,13 & 0,11 & 0,18 & 0,17 \\
\hline Óxido crômico (\%) & 0,39 & 0,34 & 0,43 & 0,39 \\
\hline Energia bruta (kcal/g) & 4,97 & 4,79 & 4,86 & 4,80 \\
\hline
\end{tabular}

1: ração 1 (quirera de arroz); ração 2 (milho); ração 3 (farinha de mandioca); e ração 4 (sorgo)

2: adição por quilograma de produto: Ferro $120 \mathrm{mg}$, Cobre $15 \mathrm{mg}$, Magnésio $8 \mathrm{mg}$, Zinco $150 \mathrm{mg}$, Iodo $2 \mathrm{mg}$, Selênio 0,2mg, Vitamina A 12000UI, Vit. D3 1000UI, Vit. E 100UI, Tiamina 8mg, Riboflavina 10mg, Ácido pantotênico 50mg, Niacina 60mg, Piroxidina 6mg, Ácido fólico 0,90mg e Vit. $B_{12} 0,1 \mathrm{mg}$.

3: Mold Zap Aquativa ${ }^{\circledR}$. Composição: dipropionato de amônia, ácido acético, ácido sórbico e ácido benzóico Alltech do Brasil Agroindustrial Ltda.

4: Banox ${ }^{\circledR}$. Composição: BHA, BHT, galato de propila e carbonato de cálcio - Alltech do Brasil Agroindustrial Ltda.

Nas rações e fezes foram determinados, segundo a metodologia descrita pela AOAC (Official..., 1996), os teores de matéria seca (metodologia 4.1.06), proteína bruta (metodologia 4.2.02), gordura em hidrólise ácida (metodologia 4.5.02) e matéria mineral (metodologia 4.1.10). A energia bruta foi determinada em calorímetro ${ }^{1}$. A lignina em detergente ácido (Van Soest) foi quantificada seguindo-se a metodologia descrita por Silva e Queiroz (2002). Para a determinação do óxido crômico, utilizou-se o método colorimétrico de Fenton e Fenton (1979).

${ }^{1}$ Parr ${ }^{\circledR}$ (modelo 1281) - Parr Instrument Company, Moline, Illinois, U.S.A.
As CIA foram quantificadas com base nas descrições de McCarthy et al. (1974) e van Leeuwen et al. (1996), porém com adaptações na metodologia original. Para a determinação das concentrações deste indicador nas amostras, pesaram-se três gramas de fezes e cinco gramas de ração em cadinho de vidro de fundo poroso. Estes foram posteriormente levados à mufla à temperatura de $450^{\circ} \mathrm{C}$ por 12 horas. As cinzas remanescentes no cadinho após a queima foram imersas em $50 \mathrm{ml}$ de solução de $\mathrm{HCl}-3 \mathrm{~N}$ e mantidas em banho-maria a $90^{\circ} \mathrm{C}$ por um período de 30 minutos. Em seguida, foram filtradas a vácuo e lavadas com água destilada aquecida até a retirada do excesso de ácido. Repetiu-se o tratamento ácido uma segunda vez buscando 
maximizar a eliminação do óxido crômico das amostras. Após o segundo banho em solução ácida, as cinzas remanescentes nos cadinhos foram queimadas durante quatro horas à temperatura de $550^{\circ} \mathrm{C}$.
A taxa de recuperação (TR) dos indicadores e os coeficientes de digestibilidade aparente dos nutrientes (CDAN) e da matéria seca (CDAMS) foram calculados, pelo método dos indicadores, com as equações a seguir:

$$
\begin{gathered}
\text { TR } \%=\frac{\text { indicador ingerido }(\mathrm{g}) \times 100}{\text { indicador excretado }(\mathrm{g})} \\
\text { CDAN }(\%)=100-\left(100 \times \frac{\% \text { indicador alimento }}{\% \text { indicador fezes }}\right) \times\left(\frac{\% \text { nutriente fezes }}{\% \text { nutriente alimento }}\right) \\
\text { CDAMS }(\%)=100 \times\left(1-\frac{\% \text { indicador alimento }}{\% \text { indicador fezes }}\right)
\end{gathered}
$$

Pela CT os CDA foram calculados com a seguinte fórmula:

$$
\operatorname{CDA}(\%)=\frac{\text { nutriente ingerido }(\mathrm{g})-\text { nutriente excretado }(\mathrm{g}) \times 100}{\text { nutriente ingerido }(\mathrm{g})}
$$

$\mathrm{O}$ arranjo dos tratamentos seguiu um esquema em parcela subdividida com medidas repetidas, sendo as parcelas constituídas pelas quatro rações e as subparcelas os quatro métodos de avaliação da digestibilidade, em um delineamento inteiramente ao acaso, com seis animais para cada ração, totalizando 24 gatos. Os dados foram submetidos à análise de variância, e as médias comparadas pelo teste Tukey a $5 \%$ de probabilidade. Essas análises foram realizadas com auxílio do programa computacional SAS (Schlotzhauer e Littell, 1997).

\section{RESULTADOS E DISCUSSÃO}

O consumo médio de ração, assim como o peso dos animais não diferiu entre os grupos experimentais (dados não apresentados). A interação ração $\mathrm{x}$ método foi significativa $(\mathrm{P}<0,05)$ e, desse modo, os métodos foram comparados em cada ração. A digestibilidade não foi influenciada pelos métodos nos grupos que receberam as rações 2, 3 e 4, mas foi menor $(\mathrm{P}<0,05)$ quando estimada com o uso da lignina no grupo que recebeu a ração 1 (Tab. 2).

A lignina apresentou baixa TR na ração 1 , com valores menores que os demais indicadores $(\mathrm{p}<0,05)$, explicando o porque da menor digestibilidade estimada por este indicador nesta ração. $\mathrm{Cr}_{2} \mathrm{O}_{3}$ e CIA apresentaram TR semelhantes entre si $(\mathrm{P}>0,05)$ e mais uniformes, resultando em menores coeficientes de variação (Tab. 3).

No presente experimento, a obtenção de elevada TR e baixo coeficiente de variação dos resultados indicam que o $\mathrm{Cr}_{2} \mathrm{O}_{3}$ é um substância índice passível de emprego para gatos. As diferenças entre os CDA determinados pela CT e estimado por este indicador foram, para a proteína bruta, de apenas 0,02 pontos percentuais para a ração 1 , de 0,18 pontos percentuais para a ração 2 , de 0,59 pontos percentuais para a ração 3 e de 1,54 pontos percentuais para a ração 4 . Kane et al. (1981) não observaram diferenças entre o método de CT e do $\mathrm{Cr}_{2} \mathrm{O}_{3}$ na determinação dos CDA dos nutrientes de oito rações para gatos. Os autores não apresentam, no entanto, as TR do indicador. Presume-se que tenham sido superiores a $100 \%$, em virtude dos maiores coeficientes de digestibilidade encontrados por este método quando comparados à CT. No entanto, as TR do $\mathrm{Cr}_{2} \mathrm{O}_{3}$ podem variar entre os estudos e ser mais ou menos satisfatórias. Andreasi (1956) verificou TR de 97,8\% enquanto Hill et al. (1996) a obtiveram de apenas $87 \%$, em trabalhos com cães.

Ao estudarem a CIA como indicador, Lôbo Jr. et al. (2001) encontraram TR de 93,9\% para cães e Rowan et al. (1991) de 90,0\% para suínos, dados ligeiramente inferiores à média encontrada no presente estudo, de $97,3 \%$. 
Tabela 2. Coeficientes de digestibilidade aparente (média \pm erro-padrão da média) das rações determinados pelo método de coleta total (CT) e pelos indicadores óxido crômico $\left(\mathrm{Cr}_{2} \mathrm{O}_{3}\right)$, lignina e cinzas insolúveis em ácidos (CIA), usadas para cães

\begin{tabular}{|c|c|c|c|c|}
\hline Ração & $\mathrm{CT}$ & $\mathrm{Cr} 2 \mathrm{O} 3$ & Lignina & CIA \\
\hline \multicolumn{5}{|c|}{ Matéria seca } \\
\hline 1 & $81,21 \pm 2,0 \mathrm{a}$ & $81,00 \pm 1,1 \mathrm{a}$ & $30,97 \pm 10,0 b$ & $79,99 \pm 1,6 \mathrm{a}$ \\
\hline 2 & $77,09 \pm 1,4^{\mathrm{a}}$ & $77,21 \pm 0,3 \mathrm{a}$ & $69,19 \pm 4,0 \mathrm{a}$ & $75,92 \pm 1,5 \mathrm{a}$ \\
\hline 3 & $79,24 \pm 0,9^{\mathrm{a}}$ & $78,61 \pm 0,8 \mathrm{a}$ & $83,33 \pm 1,4 a$ & $79,00 \pm 2,2 \mathrm{a}$ \\
\hline 4 & $74,46 \pm 1,4^{\mathrm{a}}$ & $72,39 \pm 0,6 \mathrm{a}$ & $73,79 \pm 1,3 \mathrm{a}$ & $73,58 \pm 0,8 \mathrm{a}$ \\
\hline \multicolumn{5}{|c|}{ Proteína bruta } \\
\hline 1 & $86,69 \pm 1,9^{a}$ & $86,67 \pm 1,3 \mathrm{a}$ & $41,97 \pm 9,8 b$ & $85,90 \pm 1,7 \mathrm{a}$ \\
\hline 2 & $81,92 \pm 1,6^{\mathrm{a}}$ & $82,10 \pm 0,7 \mathrm{a}$ & $75,72 \pm 3,5 \mathrm{a}$ & $81,02 \pm 1,6 \mathrm{a}$ \\
\hline 3 & $82,04 \pm 0,8^{\mathrm{a}}$ & $81,45 \pm 1,0 \mathrm{a}$ & $85,58 \pm 1,2 \mathrm{a}$ & $81,78 \pm 2,0 \mathrm{a}$ \\
\hline 4 & $79,45 \pm 1,5^{\mathrm{a}}$ & $77,91 \pm 0,5 \mathrm{a}$ & $79,10 \pm 1,0 \mathrm{a}$ & $78,85 \pm 0,7 \mathrm{a}$ \\
\hline \multicolumn{5}{|c|}{ Gordura em hidrólise ácida } \\
\hline 1 & $86,77 \pm 1,8^{\mathrm{a}}$ & $86,66 \pm 1,4 a$ & $44,06 \pm 7,4 b$ & $85,92 \pm 1,7 \mathrm{a}$ \\
\hline 2 & $84,59 \pm 0,9^{\mathrm{a}}$ & $84,60 \pm 0,6 \mathrm{a}$ & $79,29 \pm 2,8 \mathrm{a}$ & $83,81 \pm 0,9 \mathrm{a}$ \\
\hline 3 & $88,93 \pm 1,0 \mathrm{a}$ & $88,65 \pm 0,9 a$ & $91,32 \pm 0,6 a$ & $88,91 \pm 1,3 \mathrm{a}$ \\
\hline 4 & $83,12 \pm 0,6^{\mathrm{a}}$ & $81,71 \pm 0,3 \mathrm{a}$ & $82,57 \pm 1,1 \mathrm{a}$ & $82,48 \pm 0,6 \mathrm{a}$ \\
\hline \multicolumn{5}{|c|}{ Matéria orgânica } \\
\hline 1 & $86,62 \pm 1,3^{\mathrm{a}}$ & $86,48 \pm 0,5 \mathrm{a}$ & $36,18 \pm 15,8 b$ & $85,79 \pm 0,9 \mathrm{a}$ \\
\hline 2 & $81,70 \pm 1,2^{\mathrm{a}}$ & $81,80 \pm 0,3 \mathrm{a}$ & $75,43 \pm 3,2 \mathrm{a}$ & $80,77 \pm 1,2 \mathrm{a}$ \\
\hline 3 & $83,96 \pm 0,8^{\mathrm{a}}$ & $83,47 \pm 0,7 \mathrm{a}$ & $87,15 \pm 1,1 \mathrm{a}$ & $83,72 \pm 1,9 \mathrm{a}$ \\
\hline 4 & $78,59 \pm 1,2^{\mathrm{a}}$ & $76,87 \pm 0,6 \mathrm{a}$ & $80,47 \pm 2,6 \mathrm{a}$ & $77,88 \pm 0,6 \mathrm{a}$ \\
\hline \multicolumn{5}{|c|}{ Energia bruta } \\
\hline 1 & $86,55 \pm 1,4^{\mathrm{a}}$ & $86,43 \pm 0,7 \mathrm{a}$ & $37,12 \pm 14,2 b$ & $85,72 \pm 1,0 \mathrm{a}$ \\
\hline 2 & $81,55 \pm 1,1^{\mathrm{a}}$ & $81,63 \pm 0,4 \mathrm{a}$ & $75,15 \pm 3,4 a$ & $80,62 \pm 1,2 \mathrm{a}$ \\
\hline 3 & $83,85 \pm 0,8^{\mathrm{a}}$ & $83,35 \pm 0,7 \mathrm{a}$ & $87,09 \pm 0,9 \mathrm{a}$ & $83,61 \pm 1,9 \mathrm{a}$ \\
\hline 4 & $78,56 \pm 1,2^{\mathrm{a}}$ & $76,83 \pm 0,5 \mathrm{a}$ & $78,01 \pm 1,1 \mathrm{a}$ & $77,85 \pm 0,6 \mathrm{a}$ \\
\hline
\end{tabular}

Médias seguidas por letras distintas na linha diferem entre si pelo teste Tukey $(\mathrm{P}<0,05)$.

Tabela 3. Taxa de recuperação (\%) dos indicadores óxido crômico $\left(\mathrm{Cr}_{2} \mathrm{O}_{3}\right)$, lignina e cinzas insolúveis em ácido (CIA) das rações experimentais (média \pm erro-padrão da média), usadas para cães

\begin{tabular}{cccc}
\hline \multirow{2}{*}{ Ração } & Cr2O3 & Lignina & CIA \\
\cline { 2 - 4 } & & Taxa de recuperação (\%) & \\
\hline 1 & $98,06 \pm 5,8^{\mathrm{a}}$ & $25,91 \pm 4,3 \mathrm{~b}$ & $93,53 \pm 4,0 \mathrm{a}$ \\
2 & $100,56 \pm 6,2^{\mathrm{a}}$ & $81,16 \pm 11,8 \mathrm{a}$ & $95,26 \pm 1,4 \mathrm{a}$ \\
3 & $97,27 \pm 4,2^{\mathrm{a}}$ & $128,81 \pm 12,2 \mathrm{a}$ & $103,22 \pm 9,6 \mathrm{a}$ \\
4 & $92,54 \pm 4,6^{\mathrm{a}}$ & $99,67 \pm 10,0 \mathrm{a}$ & $97,02 \pm 5,4 \mathrm{a}$ \\
\hline Média & $97,11 \pm 2,5$ & $83,88 \pm 9,13$ & $97,26 \pm 2,9$ \\
CV $(\%)$ & 12,8 & 53,4 & 14,4 \\
\hline
\end{tabular}

Médias seguidas por letras distintas na linha diferem entre si pelo teste Tukey $(\mathrm{P}<0,05)$.

$\mathrm{CV}=$ coeficiente de variação.

Van Keulen e Young (1977), ao estudarem a CIA em ovinos, verificaram que, apesar dos CDA obtidos com o indicador terem sido semelhantes aos determinados pela CT, alimentos com menor teor de CIA $(0,21 \%)$ apresentaram maior variabilidade dos resultados. Os ingredientes vegetais comumente empregados nas rações para felinos não apresentam elevadas concentrações de CIA, como pode ser observado pelos resultados de Zeoula et al. (1992), que constataram concentrações de CIA de $0,67 \%$ no farelo de soja, $0,14 \%$ no milho moído, $0,15 \%$ na raspa de mandioca e $0,24 \%$ no sorgo moído.

Thonney et al. (1985) verificaram que teores de CIA nas rações inferiores a $0,75 \%$ aumentam os 
erros na quantificação laboratorial desta substância, sendo necessário número maior de repetições para uma mesma amostra a fim de que sejam obtidos resultados analíticos confiáveis. Embora no presente estudo os resultados referentes à taxa de recuperação das CIA tenham sido adequados para todas as rações, suas concentrações nas dietas, entre $0,11 \%$ e $0,18 \%$, foram inferiores aos valores mínimos recomendados por Thonney et al. (1985).

A TR da lignina foi altamente variável entre as quatro dietas deste estudo; na ração 3 a TR foi de $128 \%$ e na ração $1,25 \%$, o que resultou em elevado coeficiente de variação, 53,4\%. As diferenças entre os CDA determinados pela CT e estimadas por esse indicador foram, para a proteína bruta, 44,72 para a ração $1,6,20$ para a ração 2, 3,54 para a ração 3 e 0,35 pontos percentuais para a ração 4 , indicando uma substância índice inadequada, que pode sub ou superestimar a digestibilidade dos alimentos.

A lignina em detergente ácido é relativamente inespecífica, sofrendo interferências de outros compostos presentes no alimento ou nas fezes, que podem ser quantificados como lignina (Cherney, 2000). Fadel et al. (1988) demonstraram que os teores de lignina praticamente dobraram com a extrusão de um alimento. A formação de produtos da reação de Maillard, resultantes da ligação entre os grupos amino e carbonil do alimento, pode explicar o aumento nas concentrações de lignina após a extrusão das rações, uma vez que é conhecido que a presença de proteínas danificadas pelo calor induz a uma elevação na quantificação laboratorial da lignina (Chuyen, 1998).

Mesmo sabendo-se que a lignina não é digerida, autores encontraram digestão ileal e fecal negativa da substância, o que sinaliza a formação de compostos resistentes à ação do $\mathrm{H}_{2} \mathrm{SO}_{4}$ durante a análise laboratorial ou mesmo a produção de artefatos de lignina no trato gastrointestinal dos animais, que quando empregados na fórmula de cálculo da digestibilidade resultaram em valores negativos, ou seja, maior recuperação fecal do que ingestão do composto (Graham et al., 1986 citado por Fadel et al., 1988). Isso pode explicar a recuperação superior a 100\% desta substância índice na ração 3 , no presente experimento.
As diferenças nas propriedades físicas das rações, consumo alimentar pelos animais e tipo de alimento são fatores que contribuem para as variações nas concentrações fecais e na taxa de passagem dos indicadores (Iturbide, 1967). A composição química da lignina dos alimentos é bastante variável, uma vez que este polímero é composto por unidades de p-cumaril álcool, coniferil álcool e sinapil álcool, que variam amplamente em proporções de acordo com a região anatômica em que a lignina está presente na planta, o estágio de maturidade e entre os diferentes vegetais (Sundstøl e Owen, 1984). As diferenças entre as ligninas presentes no sorgo, milho, quirera de arroz e farinha de mandioca, bem como a reação destas ao tratamento de extrusão, podem ter sido responsáveis pela variação nas taxas de recuperação deste indicador e justificar, por exemplo, o desaparecimento parcial desta durante sua passagem pelo trato digestório na $\mathrm{R} 1$, levando à baixa TR do indicador e à subestimativa dos CDA da ração. Isso sinaliza a importância de se testar várias dietas, com diferentes alimentos, no estudo de indicadores internos.

\section{CONCLUSÕES}

$\mathrm{O} \mathrm{Cr}_{2} \mathrm{O}_{3}$ e a CIA apresentaram TR satisfatórias em gatos, podendo ser utilizados como indicadores de digestibilidade nessa espécie. A lignina não se mostrou um indicador adequado.

\section{REFERÊNCIAS BIBLIOGRÁFICAS}

ASSOCIATION OF American Feed Control Officials. Dog and cat food substantiation methods - Official Publication. Ottawa, 2004. 444p.

ANDREASI, F. Estudos de métodos indiretos (óxido crômico e lignina) para a determinação da digestibilidade aparente no cão. 1956. 60f. Tese (Livre Docência) - Faculdade de Medicina Veterinária e Zootecnia, Universidade de São Paulo, São Paulo.

BASTARACHE, E. Chromium and compounds. disponível em: $\quad<$ http://ceramicmaterials.com/cermat/education/182.html.> acessado em: 20 de nov. 2005.

CARCIOFI, A.C.; PRADA, F.; MORI, C.S. Uso de indicadores internos na avaliação da digestibilidade aparente de alimentos para gatos - comparação de métodos. Ciênc. Rural, v.28, p.299-302, 1998. 
CHERNEY, D.J.R. Characterization of forages by chemical analysis. In: GIVENS, D. J.; OWENS, E.; OMED, H.M. et al. (Eds.). Forage evaluation in ruminant nutrition. Oxon: CABI, 2000. p.281-300.

CHUYEN, N. V. Maillard reaction and food processing (application aspects). In: SHAHIDI, F.; HO, C.T.; VanCHUYEN, N. (Eds.). Process-induced chemical changes in food. New York: Springer, 1998. p.213-234.

CRANE, S. W. Introduction to commercial pet foods. In: HAND, M. S.; THATCHER, C.D.; REMILLARD, R.L. et al. (Eds). Small animal clinical nutrition. 4.ed. Topeka: Mark Morris Institute, 2000. p.111-126.

FADEL, J.G.; NEWMAN, C.W.; NEWMAN, R.K. et al. Effects of extrusion cooking of barley on ileal and fecal digestibilities of dietary components in pigs. Can. J. Anim. Sci., v.68, p.891-897, 1988.

FENTON, T.W.; FENTON, M. An improved procedure for the determination of chromic oxide in feed and feces. Can. J. Anim. Sci., v.59, p.631-634, 1979.

FERREIRA, A.D.Q. O impacto do crômio nos sistemas biológicos. Quim. Nova, v.25, p.572-578, 2002.

GRAHAM, H.; HESSELMAN, K.; AMAN, P. The influence of wheat bran and sugar-beet pulp on the digestibility of dietary components in a cereal-based diet. J. Nutr. v.116, p.242-251, 1986.

HENDRIKS, W.H.; MOUGHAN, P.J.; TARTTELIN, M.F. Gut endogenous nitrogen and amino acid excretions in adult domestic cats fed a protein-free diet or an enzymatically hydrolyzed casein- based diet. J. Nutr., v.126, p.955-962, 1996.

HILL, R.C.; BURROS, C.F.; ELLISON, G.W. et al. The use of chromic oxide as a marker for measuring small intestinal digestibility in cannulate dogs. J. Anim. Sci., v.74, p.1629-1634, 1996.

ITURBIDE, C. A. El óxido crómico como indicador externo para estimar producción fecal y consumo en las pruebas de digestibilidad. Turrialba, v.17, p.304-313, 1967.

KANE, E.; MORRIS, J.G.; ROGERS, Q.R. Acceptability and digestibility by adults cats of diets made with various sources and levels of fat. J. Anim. Sci., v.53, p.1516-1523, 1981.

LÔBO Jr., M.F.; RESENDE, A.S.C.; SALIBA, E.O.S. et al. Coeficientes de digestibilidade aparente pelos métodos de indicadores e coleta total de fezes em cães. Arq. Bras. Med. Vet. Zootec., Belo Horizonte, v.53, p.691-694, 2001.

McCARTHY, J.F.; AHERNE, F.X.; OKAI, D.B. Use of $\mathrm{HCl}$ insoluble ash as an index material for determining apparent digestibility with pigs. Can. J. Anim. Sci., v.54, p.107-109, 1974.
NUTRIENT requirements of cats. Washington D.C.: National Academy, 1986. 78p.

OFFICIAL methods of analysis. 16.ed. Gaithersburg: AOAC, 1996. v.1, chap. 4, P.1-45.

PAULING, L. A. Química geral. 2.ed. Rio de Janeiro: W. H. Freeman and Company, 1966. p.679-692.

PEACHEY, S.E.; DAWSON, J.M.; HARPER, E.J. Gastrointestinal Transit times in young and old cats. Comp. Biochem. Physiol., v.126, part A, p.85-90, 2000.

PENCOVIC, T. A.; MORRIS, J. G. Corn and wheat starch utilization by the cat. J. Anim. Sci., v.41, p.325, 1975.

ROWAN, A.M.; MOUGHAN, P.J.; WILSON, M.N. Acid-insoluble ash as a marker compound for use in digestibility studies with humans. J. Sci. Food Agric., v.54, p.269-274, 1991.

SAHA, D. C.; GILBREATH, R. L. Analytical recovery of chromium from diet and faeces determined by colorimetry and atomic absorption spectrophotometry. $J$. Sci. Food Agric., v.55, p.433-446, 1991.

SCHLOTZHAUER, S.; LITTELL, R. C. SAS system for elementary statistical analysis. 2.ed. Cary: SAS Institute, 1997, 456p.

SILVA, D. J.; QUEIROZ, A. C. O método Van Soest na determinação da qualidade das forragens. In:

Análises de alimentos: métodos químicos e biológicos. Viçosa: UFV, 2002. p.97-128.

SUNDSTØL, F.; OWEN, E. Carbohidratos y su metabolismo en los animals no ruminantes. In:

Developments in animal and veterinary sciences: Straw and others fibrous by-products as feed. Oxford: Elsevier, 1984. p.335-367.

THONNEY, M.L.; PALHOF, B.A.; De CARLO, M.R. et al. Sources of variations of dry matter digestibility measured by the acid insoluble ash marker. J. Dairy Sci., v.68, p.661-668, 1985.

VAN KEULEN, J.; YOUNG, B. A. Evaluation of acidinsoluble ash as a natural marker in ruminant digestibility studies. J. Anim. Sci., v.44, p.282-287, 1977.

VAN LEEUWEN, P.; VELDMAN, A.; BOISEN, S. et al. Apparent ileal dry matter and crude protein digestibility of rations fed to pigs and determined with the use of chromic oxide $\left(\mathrm{Cr}_{2} \mathrm{O}_{3}\right)$ and acid-insoluble ash as digestive markers. Br. J. Nutr., v.76, p.551-562,1996.

ZEOULA, L.M.; SILVA, J.F.C.; LEÃO, M.I. et al. Utilização de cinza insolúvel em ácido, óxido crômico e celulose em estudos de digestão. Rev. Soc. Bras. Zootec., v.21, p.73-82, 1992. 